\title{
Postoperative Recovery Quality after General Anesthesia in Patients Undergoing Emergency Surgery
}

\author{
I Gusti Agung Gede Utara Hartawan ${ }^{1 *}$ (D), jMade Violin Weda Yani ${ }^{2}$ D, Tjokorda Gde Agung Senapathi ${ }^{1}$ (D) I Made Gede Widnyana ${ }^{1}$ (D) \\ Christopher Ryalino ${ }^{1}$, Cynthia Dewi Sinardja ${ }^{1}$, Adinda Putra Pradhana ${ }^{1}$ (D) \\ ${ }^{1}$ Department of Anesthesiology and Intensive Care, Faculty of Medicine, Udayana University, Bali, Indonesia; ${ }^{2}$ Undergraduate \\ Study Program, Faculty of Medicine, Udayana University, Bali, Indonesia
}

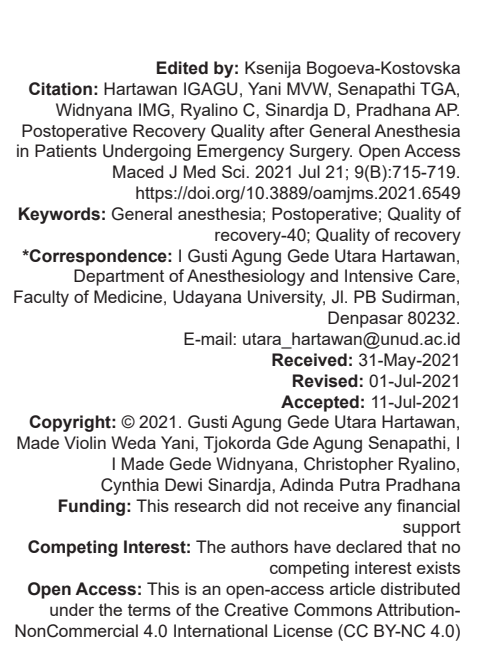

\begin{abstract}
BACKGROUND: The quality of post-operative patient recovery is part of the indicators of the quality of anesthesia services. However, side effects were still found in post-operative patients, which resulted in the speed and quality of recovery (QoR) and an increase in the length of stay for patients in the hospital.

AIM: This study aims to describe the quality of a patient's recovery after general anesthesia for patients undergoing surgery in the emergency room.

MATERIALS AND METHODS: This research is a descriptive study with a cross-sectional design conducted from February to July 2020. Patients numbered 52 people who are patients aged $18-59$ years who are willing to fill out a questionnaire QoR-40 on the day after surgery. All data were analyzed using the statistical program SPSS. The median of the QoR-40 score will be used as a cutoff point between good and poor recovery quality.

RESULTS: Fifty-two patients responded to the study with a median age of 44 years. The median QoR-40 score was 188 , with most of the good category's recovery quality (55.8\%). The middle-aged group showed better QoR ( 68.2 vs. $31.8 \%$ ), as well as the female compared to male (65 vs. $35 \%)$. Patients who underwent neurosurgery showed poor recovery 61.9 vs. $38.1 \%$ )

CONCLUSION: More than half of the patients who underwent emergency surgery under general anesthesia in the
\end{abstract} emergency room of Sanglah Hospital have good recovery quality.

\section{Introduction}

Anesthesia and intensive therapy is one type of health service that is very important in surgical and non-surgical procedures. According to the World Health Organization data, the incidence of surgery in the world has increased significantly every year [1]. There were 140 million patients who underwent surgery in 2011 and this increased in 2012 to 148 million patients [2]. The incidence of surgery in Indonesia in 2012 was 1.2 million people, equivalent to $11 \%$ of the disease burden in Indonesia, which can be overcome with surgery using anesthesia [3]. The type of anesthesia used must be adapted with the type of disease and the surgical technique performed to minimize side effects, mortality and achieve surgical procedure indicators, one of which is the quality of post-anesthesia patient recovery [4].

Recovery after anesthesia is defined as a condition when the patient returns to normal activities after receiving anesthesia [5]. A study in London shows that anesthesia services affect patient recovery quality, measured through side effects such as post-operative nausea and vomiting (PONV), headaches, and intraoperative awareness [6]. According to a 2016 study, PONV side effects can reach $30 \%$ and it cause delays in moving patients from the recovery room and increasing medical costs [7].

A 2013 systematic review with the results of studies from seven countries showed that $97 \%$ of patients had a good recovery quality [8]. A study conducted in Portugal with 114 patients showed that $76 \%$ of patients had good recovery quality, and $24 \%$ had poor recovery quality [9]. To date, there has been no descriptive study and analysis of the quality of post-anesthesia patient recovery is very limited in Bali. Therefore, this study aims to see post-operative recovery quality after general anesthesia in patients undergoing surgery in the Sanglah Hospital Bali emergency room. 


\section{Materials and Methods}

This was a cross-sectional study conducted in Sanglah General Hospital, Bali, Indonesia. After obtaining institutional ethical approval (2561/ UN14.2.2.VII.14/LP/2019), we collected data on patients underwent surgery at emergency operating theater of Sanglah General Hospital from February to July 2020. All participating patients provided written informed consent to be included in the study.

The inclusion criteria consisted of patients aged 18-59 years who underwent surgery with general anesthesia, not under treatment neuropsychiatry, and willing to be research respondents with informed consent. Exclusion criteria were unconscious patients at $24 \mathrm{~h}$ post-operative, patients with major injuries and disorders, that prevented patients from understanding the study procedure.

Patients who met the criteria were given the Quality of Recovery 40 (QoR-40) questionnaire consisting of 40 questions and requested to answer according to the patient's conditions. The collected variables were QoR-40 score, age, gender, education level, type of work, previous history of anesthesia, and type of surgery performed by the patient. All data collected were analyzed using SPSS version 25 using univariate analysis and cross-tabulation. The QoR-40 score results were categorized based on the normality test of numerical variable data using the KolmogorovSmirnov test.

\section{Results}

A total of 52 patients were involved in this study, with predominantly male subjects $(61.5 \%)$. The mean age was 39 years, with a minimum-maximum age of 19-59 years and a median value of 44. The quality of the patient's recovery was assessed based on the QoR-40 score. The mean QoR-40 score was 182 with a minimum-maximum score of 129-199. The median score is 188 , so we classified patients with a QoR-40 score of $\geq 188$ as having good recovery quality, and $<188$ as poor recovery quality. In this study, $55.8 \%$ of patients had a good quality recovery (Table 1).

In the cross-tabulation assessments (Table 2), the male patients with good and poor quality recovery are in an equal number. Meanwhile, patients with the female gender were dominated by good quality recovery $(65 \%)$. The young adults (18-35 years) and middle-aged adults (36-55 years) were dominated by patients with good recovery quality. Meanwhile, in older adults ( $>55$ years), more patients had poor recovery quality. The cross-tabulations also showed that more patients with a low education level have poor recovery
Table 1: Subjects' characteristics

\begin{tabular}{ll}
\hline Characteristics & $\mathrm{n}=52$ \\
\hline Sex, $\mathrm{n}(\%)$ & $32(61.5)$ \\
$\quad$ Male & $20(38.5)$ \\
Female & \\
Age (years) & $39 \pm 14$ \\
$\quad$ Mean \pm SD & $19-59$ \\
Min-max & \\
Type of surgery, $\mathrm{n}(\%)$ & $13(25)$ \\
Orthopedic & $6(11.5)$ \\
Hepatobiliary & $21(40.5)$ \\
Neurosurgery & $6(11.5)$ \\
Obstetric and gynecological & $1(1.9)$ \\
Integumentary & $4(7.7)$ \\
Ophthalmology & $1(1.9)$ \\
Other & \\
QoR-40 & $182 \pm 17$ \\
Mean \pm SD & $129-199$ \\
Min-max & 188 \\
Median &
\end{tabular}

quality $(66.7 \%)$. We also found that more patients with a history of anesthesia had good recovery quality $(57.1 \%)$ compared with poor recovery quality $(42.9 \%)$.

Table 2: Cross-tabulation between QoR and observed characteristics

\begin{tabular}{|c|c|c|c|}
\hline \multirow[t]{2}{*}{ Characteristics } & \multicolumn{2}{|l|}{ QoR $(n=52)$} & \multirow[t]{2}{*}{ Total } \\
\hline & Good recovery, n (\%) & Poor recovery, n (\%) & \\
\hline \multicolumn{4}{|l|}{ Sex } \\
\hline Male & $16(50.0)$ & $16(50.0)$ & $32(100)$ \\
\hline Female & $13(65.0)$ & $7(35.0)$ & $20(100)$ \\
\hline \multicolumn{4}{|l|}{ Age groups } \\
\hline Young adults ( $18-35$ years) & $11(52.4)$ & $10(47.6)$ & $21(100)$ \\
\hline Middle-aged ( $36-55$ years) & $15(68.2)$ & $7(31.8)$ & $22(100)$ \\
\hline Older adults ( $>55$ years) & $3(33.3)$ & $6(66.7)$ & $9(100)$ \\
\hline \multicolumn{4}{|l|}{ Education level } \\
\hline Low (elementary or under) & $1(33.3)$ & $2(66.7)$ & $3(100)$ \\
\hline $\begin{array}{l}\text { Middle (middle-high or high } \\
\text { school) }\end{array}$ & $22(56.4)$ & $17(43.6)$ & $39(100)$ \\
\hline High (college or beyond) & $6(60.0)$ & $4(40.0)$ & $10(100)$ \\
\hline \multicolumn{4}{|l|}{ Previous anesthesia history } \\
\hline Yes & $16(57.1)$ & $12(42.9)$ & $28(100)$ \\
\hline No & $13(54.2)$ & $11(45.8)$ & $24(100)$ \\
\hline \multicolumn{4}{|l|}{ Type of surgery } \\
\hline Orthopedic & $9(69.2)$ & $4(30.8)$ & $13(100)$ \\
\hline Hepatobiliary & $4(66.7)$ & $2(33.3)$ & $6(100)$ \\
\hline Neurosurgery & $8(38.1)$ & $13(61.9)$ & $21(100)$ \\
\hline Obstetric and gynecological & $3(50)$ & $3(50)$ & $6(100)$ \\
\hline Integumentary & $0(0)$ & $1(100)$ & $1(100)$ \\
\hline Ophthalmology & $4(100)$ & $0(0)$ & $4(100)$ \\
\hline Other & $1(100)$ & $0(0)$ & $1(100)$ \\
\hline
\end{tabular}

As for the surgery types, more patients who underwent orthopedic surgery had good recovery quality $(69.2 \%)$, as in patients who underwent hepatobiliary and ophthalmology surgeries. Meanwhile, more patients who underwent neurosurgery surgery were found to have a poor recovery quality.

\section{Discussion}

The quality of patient recovery, as reviewed by QoR-40, consists of five dimensions: physical activity, physical comfort, emotion, pain, and support. After general anesthesia, the quality of patient recovery can be influenced by various conditions, such as the patient's condition before surgery, type of surgery, duration of surgery, previous history of anesthesia, comorbidities, age, gender, education, and occupation factors. This study found that female patients are dominated by good recovery quality. This result 
contradicts Myles's study, which involved 160 postoperative patients using general anesthesia. The study showed that female patients' recovery quality was worse than that of male patients, as indicated by the mean \pm SD QoR-40 score of $162 \pm 26$ compared with $173 \pm 17$ [10]. Buchanan's study also showed that the mean \pm SD QoR-40 score in female patients was lower than that of male patients, namely, $180 \pm 19$, compared with $190 \pm 12$ at $24 \mathrm{~h}$ post-operative. The study also explained that in the QoR-40 dimension, it was found that female patients had more frequent pain, nausea, and vomiting than male patients [11].

The difference in the results of this study can be caused by age's influence on the respondents. More male respondents belong to the age group of middleaged adults and older adults $(71.9 \%)$, while more female patients belong to young adults (60\%). This condition is supported by Koenig's (2018) study, which shows that gender is also influenced by age factors that can affect post-operative recovery [12]. Furthermore, female respondents were not differentiated by menstrual status to find more details regarding postoperative recovery quality. A study by Buchanan shows that there will be an increase in progesterone production in the luteal phase of the menstrual cycle, which can reduce the need for doses of anesthetic drugs [13]. The hormone progesterone is also associated with changes in the GABA receptors' function that affects the pharmacokinetics of general anesthetic drugs [14]. The progesterone hormone can bind to intracellular receptors (especially $5 \alpha$-pregnanolone and $5 \beta$-pregnanolone), affecting protein synthesis and altering neurotransmitter-gated ion channels such as GABA-A receptors. Meanwhile, the hormone estrogen can modulate the function of the $\mathrm{N}$-methyl-D-aspartate receptor, which also has an impact on the recovery time of post-operative patients [13].

This study found that in the age group of older adults (>55 years), more patients had poor recovery quality. A study by Sveinsdottir also shows a significant correlation between old age and poorer QoR [15]. These results are in line with Myles' cohort study, which showed that old age influences the quality of poor recovery after general anesthesia, which is characterized by low QoR scores [16]. The study of Berg shows that there is a possibility that younger patients have a better QoR and a faster recovery process compared to older patients [17]. Rahman's study with 100 patients as a sample showed no significant difference in the quality of patient recovery between age groups $(p=0.554)$ after being evaluated using QoR-40 [18]. A study by Carolina shows no significant difference between the quality of patient recovery and age evaluated using QoR-15 at $24 \mathrm{~h}$ after surgery [19].

The difference in the QoR based on the patient's age is explained according to the pharmacokinetic theory of a general anesthetic drug, diazepam [20]. Diazepam, which is highly fat-soluble, can undergo drug distribution changes and excretion associated with the relative proportion of fat to total body weight with aging. A decrease in diazepam's clearance with increasing age is associated with decreased liver ability to clear diazepam through $\mathrm{N}$-demethylation. This condition causes the side effects of nausea and vomiting to last longer and can affect patient recovery quality [21].

The results of this study indicate that more patients with low levels of education have poor recovery quality. This result is in line with the findings of a study by Sveinsdottir, who found that the mean \pm SD QOR-40 score in patients with low educational levels was 178.1 \pm 18.6 , while at the secondary education level, it was $180.9 \pm 16.6$ and the higher education level is $182 \pm$ 16.1 [15]. Research by Rahman shows no significant difference in the QoR of patients who are reviewed based on the last level of education [18]. A study by Berg also showed similar results that the chi-square test showed no significant difference between the quality of patient recovery in the last education group [17]. Meanwhile, Arief's study shows that the higher the respondents' education, the higher the level of postoperative patient mobilization, which is one dimension of patient recovery [22].

Educational status is one factor that influences the quality of post-operative recovery because low education levels are significantly associated with postoperative pain levels. This condition is caused by a poor understanding of the information provided by medical personnel and an excessive level of anxiety about the impact of using anesthetics [23]. This is supported by the research of Oshodi, which shows that excessive anxiety before surgery will make it easier for individuals to feel post-operative pain. Therefore, medical personnel's preoperative information and support are needed, especially for patients with low educational levels. Patients with low education receive preoperative support and get good information from medical personnel regarding their condition to reduce preoperative psychological stress. This condition will improve the quality of patient recovery and minimize the length of stay in the hospital [24].

A study by Stessel shows that employment status is one factor that affects the quality of patient recovery based on the results of a multivariate test [25]. Rahman's study shows that there is a significant difference between the QoR in patients who work as housewives, workers with mental effort, and workers with physical effort [18].

Types of work based on physical load are also associated with preoperative physical activity intensity, which is a factor in post-operative patient recovery. A cohort study of 200 respondents who evaluated physical activity and patient recovery showed that patients with high physical activity before surgery had a $23 \%$ higher chance of having a shorter hospitality duration. This condition is also still influenced by the type of surgery the patient is 
undergoing [26]. Another study shows that as many as $85 \%$ of patients with a higher intensity of physical activity during pre-surgery will affect the quality of good recovery on the physical dimension of motion, but not on the emotional dimension. Patients with high physical activity before surgery are positively associated with shorter post-operative sick leave, shorter length of stay, and faster recovery [27].

This study shows that the QoR of patients with a history of anesthesia and without a history of anesthesia is dominated by good QoR. This result is in line with Moro's study that there is no significant difference between patients' QoR with and without prior anesthesia, evaluated by QoR40 on the $1^{\text {st }}$ post-operative day [28]. Carli's study involving 60 post-operative patients under general anesthesia also showed no difference in QoR-40 scores in the group with a history of anesthesia and without a history of previous anesthesia [29]. The history of previous anesthesia also does not affect the preoperative patient anxiety, so it does not affect patient recovery quality [30].

The prospective study with 182 patients showed contradictory results, in that a previous surgical history was associated with a recovery index in post-operative patients [31]. The findings by Stessel also show that a history of previous anesthesia is a predictor factor that is significantly associated with poor QoR due to lack of response to information provided preoperatively [25]. There are two possible reasons: the history of previous anesthesia has a bad psychological effect on the patient. Furthermore, there is a chance that there will be resistance to previous anesthetic drugs resulting in a lower anesthetic effect. The existence of resistance to the effects of anesthetics can occur in several groups of patients associated with the polymorphism of Gammaaminobutyric acid receptor type A subunit 5 (GABRA5) on etomidate use [32].

This study indicates that the QoR is more or less found in patients undergoing neurosurgical treatment. Several previous studies have shown that $90 \%$ of postcraniotomy patients will experience moderate to severe pain on the $1^{\text {st }}$ post-operative day, which corresponds to filling out the questionnaire, which is 1 day after surgery [33]. Therefore, it is possible that the patient still feels post-operative pain, thus reducing the total QoR40 score. This result is also in line with the findings by Leslie's research that patients undergoing cranial and spinal surgery have poor recovery quality, which can be influenced by various factors other than the type of surgery [34].

This study found that patients who underwent integumentary surgery, namely breast abscess incision, had poor recovery quality. General anesthesia in breast abscess cases is given to the patient before the incision to fully open the abscess cavity. Furthermore, microbiological smears and resection of tissue samples from the abscess cavity will be performed. When the operation has been completed, the wound cavity will be left open for drainage and regular irrigation. This condition can impact the patient's physical comfort as a dimension of the QoR [35]. Poor recovery conditions can also occur in resistant breast abscess cases, which is when the abscess is no longer responsive to the combination of drainage measures and the use of oral antibiotics. In this condition, it is stated that the patient will have a poor QoR for 1 week postoperatively [17].

\section{Conclusion}

The QoR-40 score results showed that most of the patients who underwent surgery with general anesthesia at the emergency room of Sanglah Hospital had a good quality recovery.

\section{References}

1. World Health Organization. Size and Distribution of the Global Volume of Surgery in 2012. Geneva: World Health Organization; 2012. Available from: http://www.who.int/bulletin/ volumes/94/3/15-159293/en. [Last accessed on $2021 \mathrm{Apr} 27$ ].

2. Meara JG, Leather AJ, Hagander L, Alkire BC, Alonso N, Ameh EA, et al. Global Surgery 2030: Evidence and solutions for achieving health, welfare, and economic development. Int $\mathrm{J}$ Obstet Anesth. 2016;25:75-8.

PMid:26597405

3. Parami P, Ryalino C. The incidence of post-operative cognitive dysfunction in elderly patients underwent elective surgery at Sanglah General Hospital. Bali J Anesthesiol. 2020;4(Suppl 2):61-3. https://doi.org/10.4103/bjoa.bjoa_109_20

4. Shirley E, Sanders J. Patient satisfaction: Implication and predictors of success. J Bone Jt Surg Am. 2013;95(10):e69.

PMid:23677370

5. Kluivers K, Riphagen I, Vierhout M, Brölmann HA, de Vet HC. Systematic review on recovery specific quality-oflife instruments. Surgery. 2008;143(2):206-15. https://doi. org/10.1016/j.surg.2007.08.017

PMid:18242337

6. Barnet S, Alagar R, Grocott M, Giannaris S, et al. Post-operative recovery and its association with health-related quality of life among day surgery patients. BioMed Cent Nurs J. 2012;11:24. PMid:23148514

7. Aribawa IGN, Senapathi TG, Widnyana IM, Hartawan IG Pradana AP, Ryalino C. Comparison between targetcontrolled infusion propofol and target-controlled inhalational anesthesia sevoflurane in mastectomy surgery in Indonesia. Bali J Anesthesiol. 2021;5:61-5. https://doi.org/10.4103/bjoa. bjoa_178_20

8. Gornall B, Myles P, Smith C, Burke J. Measurement of qualityof recovery using the QoR-40: A quantitative systematic review. $\mathrm{Br}$ J Anesth. 2013;111(2):161-9.

PMid:23471753

9. Guimaraes P, Costa M, Sousa G, Abelha F. Quality of recovery after anaesthesia measured with QoR-40: A prospective observational study. Braz J Anesth. 2016;66(4):369-75. https:// doi.org/10.1016/j.bjane.2014.11.010 
PMid:27343786

10. Myles PS, Weitkamp B, Jones K, Melick J, Hensen S. Validity and reliability of a post-operative quality of recovery score: The QoR-40. Br J Anaesth. 2000;84(1):11-5. https://doi.org/10.1093/ oxfordjournals.bja.a013366

PMid:10740540

11. Buchanan FF, Myles PS, Cicuttini F. Effect of patient sex on general anaesthesia and recovery. $\mathrm{Br} J$ Anaesth. 2011;106(6):832-9. https://doi.org/10.1093/bja/aer094 PMid:21558068

12. Koenig K. Comparing prescriptive and descriptive gender stereotypes about children, adults, and the elderly. Front Physiol. 2018;9:1086. https://doi.org/10.3389/fpsyg.2018.01086 PMid:29997558

13. Buchanan FF, MylesPS, CicuttiniF. Patientsexand its influence on generalanaesthesia.Anaesth Intensive Care. 2009;37(2):207-18. https://doi.org/10.1177/0310057x0903700201 PMid:19400484

14. Bajaj P, Raiger LK, Jain SD, Kumar S. Women emerge from general anesthesia faster than men. Middle East J Anesthesiol. 2007;19(1):173-83.

PMid:17511191

15. Sveinsdottir $\mathrm{H}$, Borgthorsdottir $\mathrm{T}$, Asgeirsdottir MT, Albertsdottir $\mathrm{K}$, Asmundsdottir LB. Recovery after same-day surgery in patients receiving general anesthesia: A cohort study using the quality of recovery-40 questionnaire. J Perianesthesia Nurs. 2016;31(6):475-84. https://doi.org/10.1016/j.jopan.2015.07.003 PMid:27931699

16. Myles PS, Bs MB, Hunt JO, Nightingale CE, Fletcher $\mathrm{H}$, Beh $\mathrm{T}$, et al. Development and psychometric testing of a quality of recovery score after general anesthesia and surgery in adults. Anesth Analg. 1999;88(1):83-90. https://doi. org/10.1213/00000539-199901000-00016

PMid:9895071

17. Berg K, Idvall E, Nilsson U, Arestedt KF, Unosson M. Psychometric evaluation of the post-discharge surgical recovery scale. J Eval Clin Pract. 2010;16(4):794-801. https://doi. org/10.1111/j.1365-2753.2009.01197.x PMid:20557414

18. Rahman AARA, Mahdy NE, Kamaly AM. Predictive factors affecting post-operative quality of recovery for patients undergoing surgery. IOSR J Nurs Heal Sci. 2017;6(3):50-60.

19. Carolina A, Sousa G, Santos C, Abelha F. Quality of recovery after anesthesia: validation of the portuguese version of the quality of recovery 15 questionnaire. Acta Med Port. 2015;28(5):567-74. https://doi.org/10.20344/amp.6129 PMid:26667859

20. Mangoni A., Jackson SH. Age-related changes in pharmacokinetics and pharmacodynamics: Basic principles and practical applications. Br J Clin Pharmacol. 2004;57(1):6-14. https://doi.org/10.1046/j.1365-2125.2003.02007.x PMid:14678335

21. Orchs H, Greenblatt D, Divoll M, Abernethy D. Diazepam kinetics in relation to age and sex. Pharmacology. 1981;23(1):24-30. https://doi.org/10.1159/000137524

PMid:7312934

22. Hamzah H, Bratha IN, Sumartono C, Utariani A, Semedi BP, Avidar YP. Comparison of outcome between patients receiving general anesthesia combined with continuous epidural anesthesia and patients receiving general anesthesia combined with intermittent epidural anesthesia. Bali $\mathrm{J}$ Anesthesiol. 2020;4:118-21. https://doi.org/10.4103/bjoa.bjoa_18_20

23. Lanitis S, Mimigianni C, Raptis D, Sourtse G, Sgourakis G, Karaliotas C. The impact of educational status on the postoperative perception of pain. Korean $\mathrm{J}$ Pain. 2015;28(4):265-74. https://doi.org/10.3344/kjp.2015.28.4.265 PMid:26495081

24. Oshodi TO. The impact of preoperative education on postoperative pain. Part 2. Br J Nurs. 2007;16(13):790-7.

PMid:17851332

25. Stessel B, Fiddelers AA, Joosten EA, Hoofwijk DM, Gramke HF, Buhre WF. Prevalence and predictors of quality of recovery at homeafterdaysurgery. Medicine(Baltimore). 2015;94(39):e1553. https://doi.org/10.1097/md.0000000000001553

PMid:26426622

26. Onerup A, Angerås U, Bock D, Börjesson M, Fagevik Olsén M, et al. The preoperative level of physical activity is associated to the post-operative recovery after elective cholecystectomy a cohort study. Int J Surg. 2015;19:35-41. https://doi.org/10.1016/j. ijsu.2015.05.023

PMid:26003290

27. Nilsson $H$, Angerås $U$, Bock $D$, Börjesson $M$, Onerup $A$, Olsen MF, et al. Is preoperative physical activity related to post-surgery recovery? A cohort study of patients with breast cancer. BMJ Open. 2016;6(1):e007997. https://doi.org/10.1136/ bmjopen-2015-007997

PMid:26769776

28. Moro ET, da Silva MA, Couri MG, da Silva Issa D, Barbieri JM. Quality of recovery from anesthesia in patients undergoing orthopedic surgery of the lower limbs. Braz J Anesthesiol. 2016;66(6):642-50. https://doi.org/10.1016/j.bjane.2015.05.001 PMid:27793240

29. de Carli D, Meletti JF, Neto NE, Martinez G, Kim AL, de Camargo RP. General anesthesia technique and perception of quality of post-operative recovery in women undergoing cholecystectomy: A randomized, double-blinded clinical trial. PLoS One. 2020;15(2):e0228805. https://doi.org/10.1371/ journal.pone.0228805

PMid:32107487

30. Jenkins K, Grady D, Wong J, Correa R, Armanious S, Chung F. Post-operative recovery: Day surgery patients' preferences. $\mathrm{Br} J$ Anaesth. 2001;86(2):272-4. https://doi.org/10.1093/ bja/86.2.272

PMid:11573673

31. Strozyk S, Wernecke K, Sehouli J, David M. Factor influencing post-operative recovery and time off work of patients with benign indication for surgery-results of a prospective study. Geburtshilfe Frauenheilkd. 2020;80(7):723-32. https://doi. org/10.1055/a-1157-8996

\section{PMid:32675834}

32. Sandhu K, Dash $\mathrm{H}$. Awareness during anaesthesia. Indian J Anaesth. 2009;53(2):148-57.

PMid:20640115

33. Vacas $\mathrm{S}$, Wiele $\mathrm{V}$. designing a pain management protocol for craniotomy: A narrative review and consideration of promising practices. Surg Neurol Int. 2017;8:291. https://doi.org/10.4103/ sni.sni_301_17

PMid:29285407

34. Leslie K, Troedel S, Irwin K, Pearce F, Ugoni A, Gillies R, et al. Quality of recovery from anesthesia in neurosurgical patients. Anesthesiology. 2003;99(5):1158-65. https://doi. org/10.1097/00000542-200311000-00024

PMid:14576554

35. Farhni M, Schwarz E, Stadlmann S, Singer G, Hauser N, HubikHuch R. Breast abscesses: Diagnosis, treatment and outcome. Breast Care. 2012;7(1):32-8. https://doi.org/10.1159/000336547 PMid:22553470 